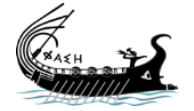

journal.phaselis.org
PHAS KLIS Issue V (2019)
Disiplinlerarası Akdeniz Araştırmaları Dergisi

Journal of Interdisciplinary Mediterranean Studies

\title{
Aiolis Bölgesi'nden Yeni Bir Yazıt ve Buluntu Yeri Üzerine
}

\author{
A New Inscription from Aiolis and Considerations About \\ Findspot
}

Murat AYDAŞ

(D) https://orcid.org/0000-0002-3915-3683

\section{Emre ERDAN}

(D) https://orcid.org/0000-0002-4389-2016

open access journals

The entire contents of this journal, Phaselis: Journal of Interdisciplinary Mediterranean Studies, is open to users and it is an 'open access' journal. Users are able to read the full texts, to download, to copy, print and distribute without obtaining the permission of the editor and author(s). However, all references to the articles published in the e-journal Phaselis are to indicate through reference the source of the citation from this journal.

Phaselis: Journal of Interdisciplinary Mediterranean Studies is a peer-reviewed journal and the articles which have had their peer reviewing process completed will be published on the web-site (journal.phaselis.org) in the year of the journal's issue (e.g. Issue IV: JanuaryDecember 2018). At the end of December 2018 the year's issue is completed and Issue V: January-December 2019 will begin.

Responsibility for the articles published in this journal remains with the authors.

Citation M. Aydaş, E. Erdan “Aiolis Bölgesi'nden Yeni Bir Yazıt ve Buluntu Yeri Üzerine". Phaselis V (2019) 197-206. http://dx.doi.org/10.18367/Pha.19013

Received Date: 03.05.2019 | Acceptance Date: 02.08.2019

Online Publication Date: 27.08.2019

Editing Phaselis Research Project

www.phaselis.org 


\title{
Aiolis Bölgesi'nden Yeni Bir Yazıt ve Buluntu Yeri Üzerine
}

\section{A New Inscription from Aiolis and Considerations About Findspot}

\author{
Murat AYDAŞ * - Emre ERDAN **
}

Öz: Koca Çay-Güzelhisar Çayı (antik Titanus-Pythikos) Havzası'nda 1860 yılında Guichon, 1881 yılında Reinach ile Baltazzi ve 1909 yıında Conze tarafından araştırmalar yapılmıştır. Bu araştırmacıların herhangi bir yazı bulamadığı aynı bölgede 2018 yılında E. Erdan başkanlığında başlayan araştırmalarda Sarıkale Tepe'de, araştırma tarihçesi verilen bölgenin ilk yazıtı keşfedilmiştir. 2018 ve 2019 yılları araştırmalarının ilk sonuçlarını içeren bu çalışma, Karystoslu Nikon'un oğlu Nikon'a ait yeni yazııı bilim dünyasına sunmakta; araştırma bölgesinde yeri aranan kayıp Tisna-Titanus yerleşiminin Sarıkale Tepe ve Kocakale Tepe'de olduğunu ileri sürmekte ve Tisna-Titanus yerleşiminin olası isimlerini tartışmaktadır.

Anahtar sözcükler: Aiolis, Tisna-Titanus, Pythikos, İzmir, Aliağa, Euboia, Karystos

Abstract: Guichon in 1860, Reinach \& Baltazzi in 1881, and Conze in 1909 conducted surveys in the Koca Çay-Güzelhisar Çayı Valley. In 2018 a survey started at a territory, the so-called Tisna, in Aiolis under the direction of E. Erdan. During the first expedition the team discovered a new inscription in a sepulchral mound in Sarıkale Tepe. They didn't find any inscription. The new inscription from this region is as follows: Nikon, son of Nikon, from Karystos. This article also discusses location and possible names of Tisna-Titanus.

Keywords: Aiolis, Tisna-Titanus, Pythicus, İzmir, Aliağa, Euboia, Karystos

\section{Euboialı Nikon'un Mezar Yazıtı}

2018 yılında E. Erdan başkanlığında bir ekip, "Tisna Antik Kenti ve Yakın Çevresi" başlıklı yüzey araştırmasında, Çandarlı Körfezi'ni, Kyme ve Myrina antik kentlerini gören Sarıkale Tepe'nin (Fig. 1) batısında bir tümülüs (Fig. 2-4) tespit etmiştir ${ }^{1}$. Kaçak kazılar ile oldukça tahrip edilmiş durumda olan üstü taş yığma 1 no'lu Tümülüs'ün içine bir dromos ile ulaşılmaktadır. Mezar, anakaya biçimlendirilerek oluşturulmuştur; iki odalı ve kline'lidir.

* Doç. Dr. Murat Aydaş, Klasik Filolog \& Epigrafist. Aydın Adnan Menderes Üniversitesi, Fen-Edebiyat Fakültesi, Arkeoloji Bölümü, Aydın, murataydas@hotmail.com | D https://orcid.org/0000-0002-3915-3683

** Dr. Öğr. Ü. Emre Erdan, Arkeolog. Aydın Adnan Menderes Üniversitesi, Fen-Edebiyat Fakültesi, Arkeoloji Bölümü, Aydın, erdanemre@gmail.com | (D) https://orcid.org/0000-0002-4389-2016

1 Tisna Antik Kenti ve Yakın Çevresi Yüzey Araştırmaları, T.C. Kültür ve Turizm Bakanlığı, Kültür Varlıkları ve Müzeler Genel Müdürlüğü ve Aliağa Belediyesi tarafından desteklenmektedir. Söz konusu kurum yetkili ve çalışanlarına teşekkür ederiz. 


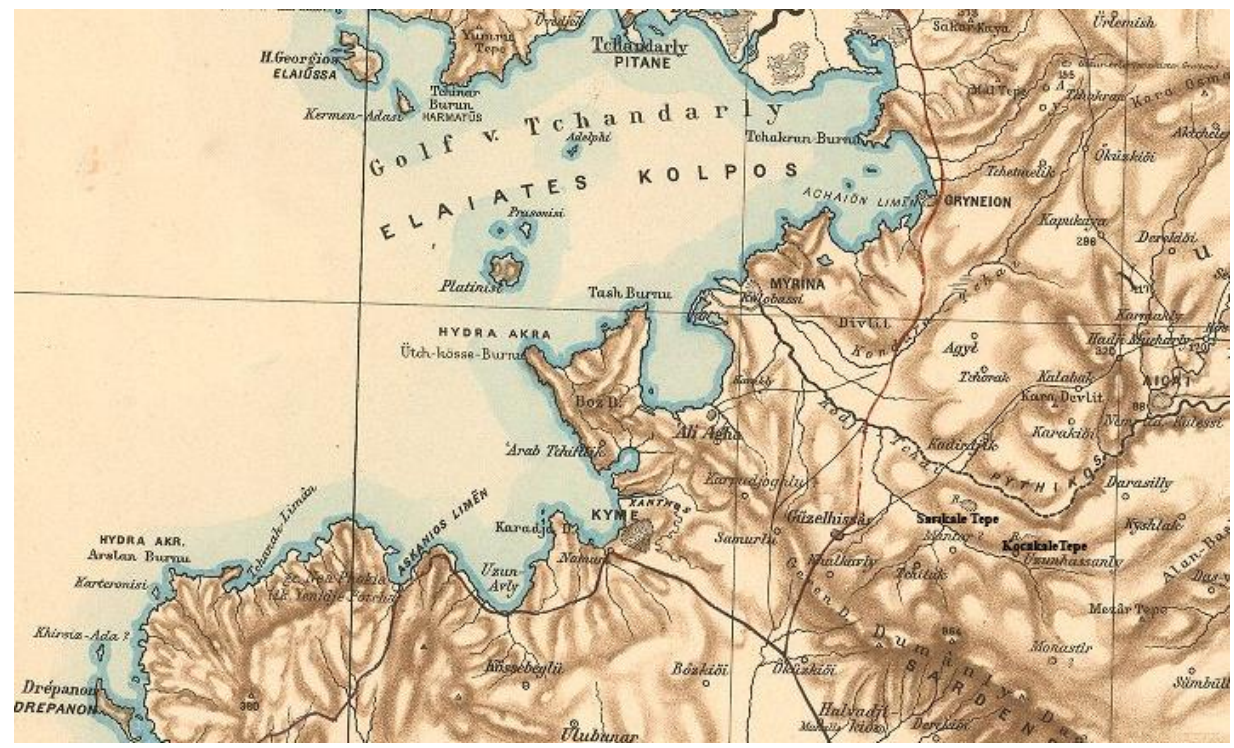

Fig. 1. Kiepert 1890 (Sarıkale Tepe ve Kocakale Tepe, Koca Çay-Pythikos Irmağı'nın altında işaretlenmiş Almanca " $R$ " [Ruinen] kısaltmalarının olduğu yerde haritaya eklenmiştir)

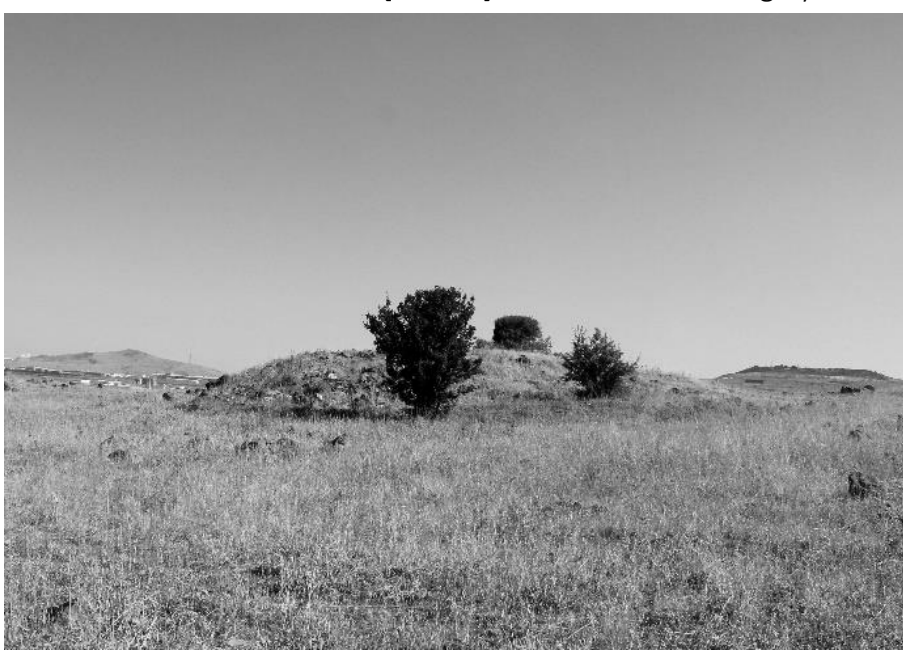

Fig. 2. Sarıkale Tepe 1 no'lu Tümülüs (Güneyden) (Tisna Antik Kenti ve Yakın Çevresi Araştırmaları Arşivi)

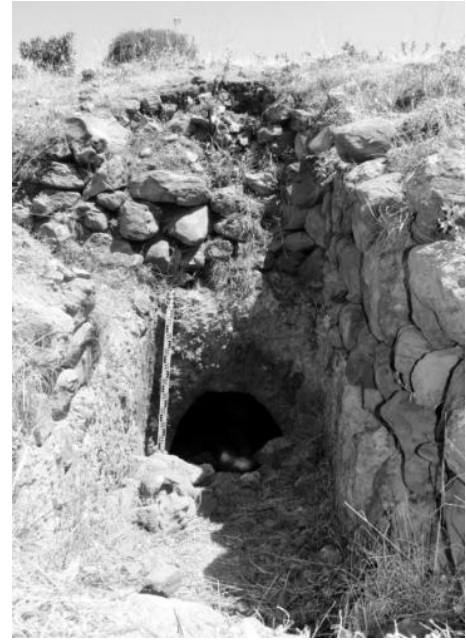

Fig. 3. Sarıkale Tepe 1 No'lu Tümülüs'ün dromos'undan görünüm

(Tisna Antik Kenti ve Yakın Çevresi Araştırmaları Arşivi)
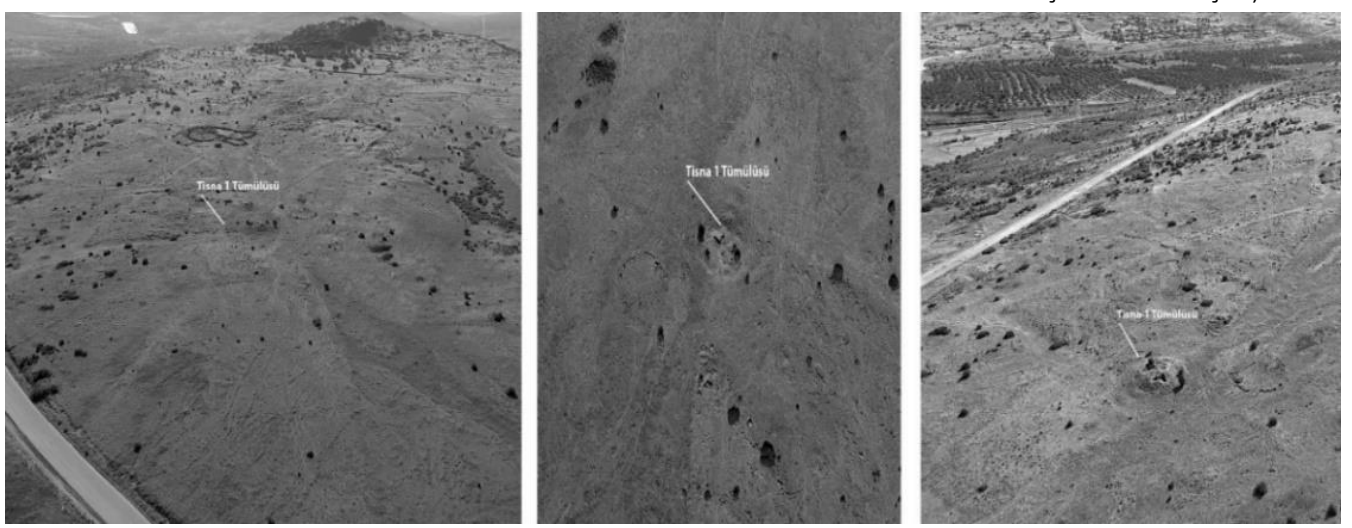

Fig. 4. Sarıkale Tepe 1 no'lu Tümülüs'ün farklı açılardan çekilmiş hava fotoğrafları (Tisna Antik Kenti ve Yakın Çevresi Araştırmaları Arşivi) 


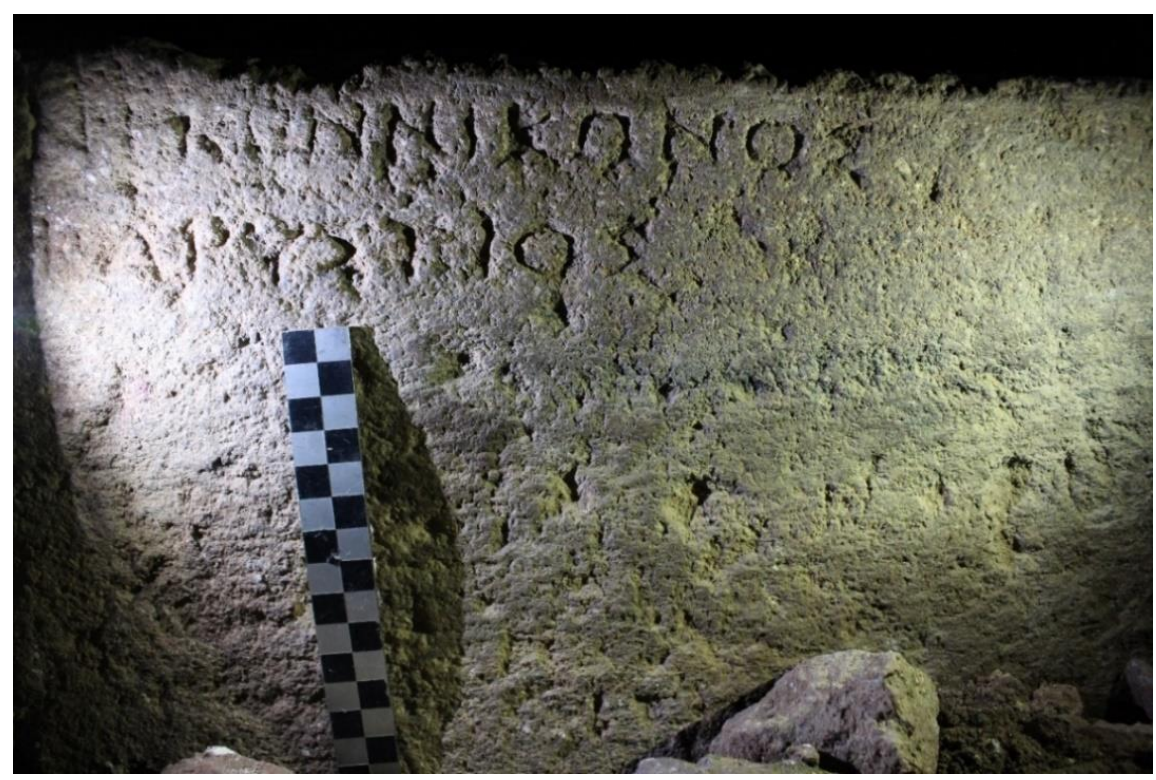

Fig. 5. Sarıkale Tepe 1 No'lu Tümülüs'de keşfedilen yazıt.

(Tisna Antik Kenti ve Yakın Çevresi Araştırmaları Arşivi)

1 no'lu Tümülüs'ün ikinci odasında, kireçtaşından yapılmış kline'ye ait olduğu düşünülen kesme blok taşlardan bir tanesi üzerinde iki satır Hellence yazıt (Fig. 5) bulunmuştur.

Ölçüleri: Yükseklik: 23 cm., genişlik: 78 cm., kalınlık: 34 cm., harf yüksekliği 1,5 cm.

Tarihlendirme: 1 No'lu Tümülüs çevresindeki yüzey buluntuları, sigma harfinin formu ve omega harfinin açıklığı nedeniyle yazıtın Klasik Dönem'e ait olduğu düşünülmektedir.

\section{Níkwv NíkwVos \\ 2 Kapúotıc.}

Nikon'un oğlu Karystoslu Nikon.

Yazıt, Aiol lehçesiyle yazılmamıştır.

1-2: IG $\|^{2} 8978$ 'de (bk. epigraphy.packhum.org), MÖ IV. yüzyıla tarihlenmiş mezar yazııında bir

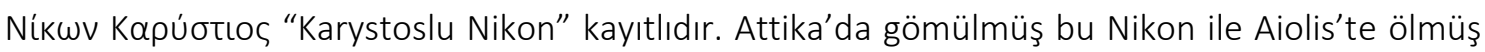
ve 2018 yılında Sarıkale Tepe'de tümülüsü keşfedilmiş Karystoslu Nikon arasında aile bağını gösteren veri henüz bulunmamaktadır. Şimdilik iki Nikon arasındaki tek bağ Karystoslu olmalarıdır.

Antikçağda "Nikon" şahıs ismi yaygın kullanılırdı. Fakat bölgede, civarda ve antikitede Karystoslu Nikon isimli sadece bu iki kişi belirlenmiştir.

Yazıtlar incelendiğinde görülmektedir ki Miletos kenti, Khairimenes'in oğlu Karystoslu Bion'a yurttaşlık hakkı vermiştir ${ }^{2}$. Aleksandreia Troas'ta, isimleri yazıtta yer almayan Karystoslu yargıçlar görev yapmış; yuttaşlık hakkı ve çeşitli onurlarla taltif edilmişlerdir ${ }^{3}$.

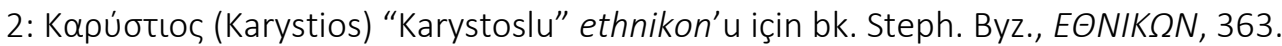

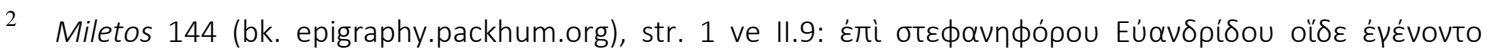

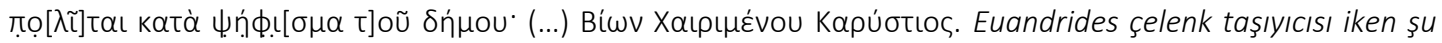
kişiler halkın kararına göre Miletos yurttaşı oldular: (...) Khairimenes'in oğlu Karystoslu Bion.

3 IMT SuedITroas 420 (bk. epigraphy.packhum.org). 
Byzantionlu Stephanos, EONIKSN, 362-363'te Karystos hakkında şunları yazmıştır:

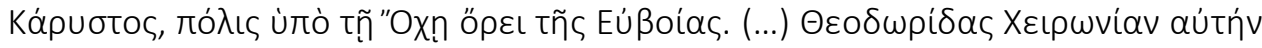

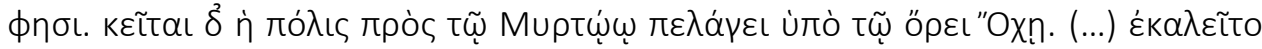



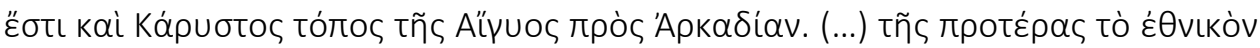

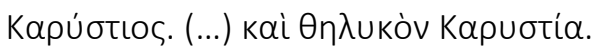

Karystos, Euboia'da Okhe Dağı'nın dibinde bir kenttir. (...) Theodoridas, o kente Kheironia der. Karystos kenti, Okhe Dağı'nın dibinde Myrtoos Denizi'nin yakınında yer alır. Aigaia adını da [bu kentte] hükümdar olan Aigaion'dan almıştır. Denizin adı da bu nedenle Aigaion Denizi olmuştur. Arkadia yakınında Aigys'te Karystos Mevkii de vardır. (...) Ilkinin ethnikon'u Karystios'tur. (...) Kadınlar için de Karystia (kullanılır).

Strabon, Geographika 10. 1. 6'da Karystos'a dair daha fazla bilgi vermiştir:









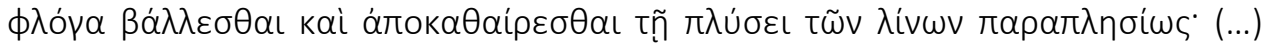

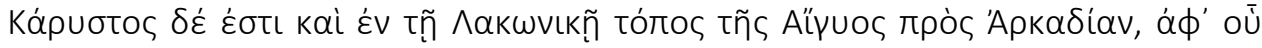

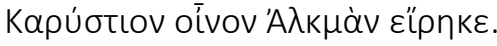

Karystos Okhe Dağı'nın dibindedir. Styra yerleşiminin ve Karystos sütunlarının üretildiği taş ocağı ile Apollon Marmarinos Tapınağı́nın yer aldığı Marmarion'un yakınındadır. Oradan deniz yoluyla Halae Araphenides'e gidilir. Karystos'ta kazınan ve işlenen taş da çıkar. Bu taş, elişi dokumalar gibi kirlenince ateşe atılır ve ketenler gibi yıkanıp temizlenir. (...) Lakonia'da Arkadia yakınında Aigys'te de, Alkman'ın bahsettiği Karystos şarabının üretildiği Karystos Mevkii vardır.

Ayrıntılı çalışmalara karşın, içerisinde yazıttan başka herhangi bir buluntuya rastlanmayan 1 No'lu Tümülüs'ün çevresinde 2018 ve 2019 yıllarında gerçekleştirilen incelemeler neticesinde, Sarıkale Tepe'deki tek tümülüsün, Nikon'un Tümülüs'ü (1 no'lu Tümülüs) olmadığı anlaşılmış; yerleşimin ana savunma duvarının dışında ve batısında kalan alanın neredeyse tamamına yayılmış şimdilik 46 tümülüs daha tespit edilmiştir ${ }^{4}$.

Sarıkale Tepe'de sürdürülen araştırmalar sırasında tespit edilen küçük buluntular, başta seramikler olmak üzere, tarihleme açısından son derece önemli veriler sunmuştur. En azından Orta Tunç Çağı örnekleri ile başlatabileceğimiz iskânın, özellikle MÖ VII-III. yüzyıllarda yoğunlaştığı, yüzeyde yoğun miktarda tespit edilen dönem seramikleri aracılığıyla net olarak görülmektedir. Bununla beraber henüz yapısı anlaşılamayan bazı sur duvarlarının kiklopik yapısı, ilerleyen yıllarda gerçekleştirilecek çalışmaların, daha erken bir yerleşim alanının varlığına da ışık tutabileceğini düşündürmektedir.

Yazıtın bulunduğu 1 no'lu Tümülüs'ü de içinde barındıran Sarıkale Tepe, yerleşimin batı uzantısını oluşturmaktadır. İki yıllık çalışmalar neticesinde, Sarıkale Tepe'nin, Orta Tunç Çağı'ndan

4 ilerleyen yıllarda gerçekleştirilecek araştırmalarla sayısının artacağını öngördüğümüz tümülüsler arasında, kaçak kazılarla en az bir tümülüsün daha tahrip edilmiş olduğu gözlemlenmiştir. Söz konusu olası nekropolis alanı ve 1 No'lu Tümülüs hakkında ayrıntılı çalışmalar araştırma ekibi tarafından yayına hazırlanmaktadır. 
Doğu Roma Imparatorluk Dönemi'ne değin neredeyse kesintisiz iskân edildiği anlaşımaktadır. Buradaki yerleşimi çevreleyen oldukça iyi korunmuş bir sur duvarı ile Arkaik Dönem'den Doğu Roma Imparatorluk Dönemi'ne tarihlenen çeşitli sur ve mekân duvarlarının varlığını tespit ettiğimiz Sarıkale Tepe'de, akropolis olarak tanımlayabileceğimiz zirve noktasında bir adet, sur duvarının hemen içerisinde de bir adet olmak üzere iki kutsal alan saptanmıştır ${ }^{5}$.

\section{Sarıkale Tepe ve Kocakale Tepe'nin Tisna ${ }^{6}$ olarak Lokalizasyonu}

Herodotos (MÖ 484-430), Tisna'yı Aiolis kentleri arasında saymamıştır. Herodotos'tan farklı olarak Plinius'un (MS 23-79) kaydettiği Aiolis kentleri ise Itale, Posidea ve Titanus'tur ${ }^{8}$.

L. Robert'e göre Titanus, aslında Titnaus'tur ${ }^{9}$. Hem bir ırmağın hem de bir kentin ismi olan Titanus Hellence Titanos'un Latince formudur. Bu irmak, Tisnaios-Titnaios ${ }^{10}$ ve Pythikos olarak da adlandırılmıştır ${ }^{11}$. Bugün ismi Koca Çay-Güzelhisar Çayı olan bu akarsu, Sarıkale Tepe ve Kocakale Tepe'nin kuzeyinden akmakta ve Kocakale Tepe'nin kuzeydoğusunda yer alan Güzelhisar Barajı́nı beslemektedir. Hafif bir meyille kuzeybatı yönüne dönen akarsu, Aliağa ilçe merkezinin kuzeyinde, Myrina antik kenti önlerinden Çandarlı Körfezi ile bütünleşir. Bölgeyi besleyen bir diğer akarsu ise Sirçe Dere'dir. Bu akarsu da Uzunhasanlar Mahallesinin güneyinden akmaktadır.

Araştırmaların son derece kısıtlı olduğu Tisna kentine dair ilk modern bilgiler, 1860'lı yıllarda yörede gezen Fransız seyyah Guichon'dan gelmektedir. Guichon, Koca Çay-Güzelhisar Çayı Vadisi'nde yaptığı gezilerde, Uzunhasanlar Mahallesi'nde bir oyukta Karabel Anıtı'na benzer bir alçak kabartma gördüğünü belirtmiştir. Bu kabartma, 1881 yılında S. Reinach ve D. Baltassi tarafından defalarca aransa da, Guichon'un ayrıntılı tanımlamasına rağmen bulunamamıştı ${ }^{12}$. En kapsamlı çalışma A. Conze tarafından 1909 yılında yapılmışıır ${ }^{13}$. Conze, kenti bulmaya yönelik düzenlediği araştırmada; yaklaşık bir plan çizmiş, kaya mezarları ve yüzeyde görünür durumdaki sur duvarlarının tanımını yapmıştır. Ekibiyle birkaç kez gelen E. Doğer ise burayı Pers işgal yılları

5 Bu kutsal alanlara dair ön gözlemleri içeren çalışmalar araştırma ekibi tarafından yayına hazırlanmaktadır.

6 "Tisna" ismine benzeyen "Tišna" kelimesi, Hitit metinlerinde lokalizasyonu belli olmayan bir dağın adıdır. Erdan \& Tiro 2018, 89-101.

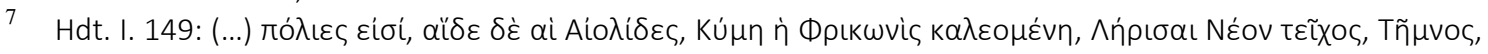

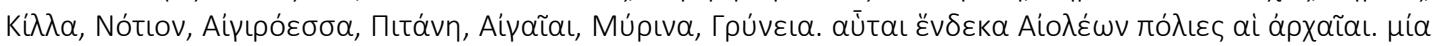

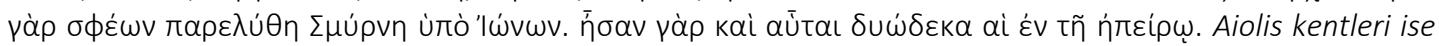
şunlardır: Phrikonis olarak da adlandırılan Kyme, Lerisai, Neon Teikhos, Temnos, Killa, Notion, Aigiroessa, Pitane, Aigaiai, Myrina, Gryneia. Bu on bir kent, Aiollerin eski kentleridir. Onların kentlerinden biri, Smyrne, Ionialılar tarafından Aiollerin elinden alınmıştır. Oysa anakaradaki Aiol kentlerinin sayısı da on iki idi.

8 Plin., nat. V. 32: Aeolis proxima est, (...) ibi a Phocaea Ascanius portus; dein fuerat Larisa, sunt Cyme, Myrina quae Sebastopolim se vocat, et intus Aegaeae, Itale, Posidea, Neon Tichos, Temnos. in ora autem Titanus amnis et civitas ab eo cognominata; fuit et Grynia, nunc tantum portus, olim insula adprehensa. Çok yakında Aiolis vardır. (...) Oradaki Askanios Limanı, Phokaia'dan ileride yer alır. Askanios Limanı'ndan sonra, daha önce Larisa'nın olduğu yerde bugün Kyme ve kendisini Sebastopolis olarak adlandıran Myrina bulunmaktadır. İc kesimde Aigaiai, Itale, Posidea, Neon Teikhos ve Temnos vardır. Deniz kıyısında ise Titanus Irmağı ve ismini bu ırmaktan alan Titanus kenti bulunur. Eskiden göze görünen bir ada, şimdi sadece bir liman olan Grynia da deniz kıyısındadır.

9 Robert 1970, 169: "Le Titanus de Pline s'appelait en réalité Titnaus".

10 Leschhorn \& Franke 2002, 294, dn. 1: "Tisnaios ist wohl der ältere Name des Flussgottes, der zum Eponymen der Stadt Tisna wurde; später hieß er Titnaios".

11 Pottier \& Reinach 1886, 14; Bean 2001, 87.

12 Reinach 1891, 107-109; Doğer 2017, 189.

13 Conze 1911, 1-12. 
içerisinde gözetleme amaçı bir askeri karakol olarak değerlendirmiştir ${ }^{14}$. B. V. Head'e bakılırsa Tisna, Kyme ve Aigai'ın yakınındadır ${ }^{15}$. J. Keil'a bakılırsa Tisna, Koca Çay Vadisi'nde, Kyme ile Aigai arasında ve Kyme civarındadır ${ }^{16}$. L. Robert'e göre Tisna, büyük olasılıkla Kyme, Myrina ve Aigai arasındadır $^{17}$. L. Zgusta'ya bakılırsa Tisna, Kyme ve Aigai arasında bugünkü Koca Çay Vadisi'ndedir ${ }^{18}$.

Varlığı, bölgeden yurtiçi ve yurtdışı çeşitli müze veya müzayede şirketlerine götürülen kaçak kazı buluntuları sayesinde bilinen, fakat yazıt olmadığı için yeri bugüne kadar saptanamayan Tisna kentini bulmak için, 2018 yılında E. Erdan başkanlığında bir ekip, "Tisna Antik Kenti ve Yakın Çevresi" başlıklı Yüzey Araştırması'na başlamıştır. Çalışmalar, Kocakale Tepe ve Sarıkale Tepe'de yoğunlaşmıştır.

Titanus-Titnaios-Tisnaios-Pythikos Irmağı'nın (bugün Koca Çay-Güzelhisar Çayı) konumu ve yayına hazırlanmakta olan 2018 ve 2019 yılları yüzey araştırması buluntuları, ekibe, TitanusTisna kentinin, yaklaşık 250-350 m rakımlı Kocakale Tepe ve Sarıkale Tepe üzerinde yer aldığını düşündürmektedir. Çandarlı (Elaitikos) Körfezi'ne bakan bu iki tepe, güneyde Uzunhasanlar ve Çıtak, güneydoğuda Karakuzu, güneybatıda ise Güzelhisar Mahalleleri ile çevrilidir.

\section{Tisna'nın Yerleșim Statüsü ve İsimleri}

Yerleşimin hukuki statüsünün "kent (polis)" olduğunu gösteren Tisna ${ }^{19}$ sikkelerinde (Fig. 6),

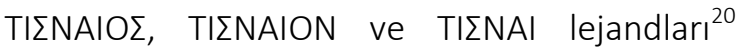
okunur.

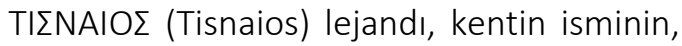
Myrina gibi alpha impurum Tisna; Aigai gibi plurale tantum Tisnai (Fig. 6'daki TIINAI lejandı da bu düşünceyi desteklemektedir) ve Gryneia gibi Tisnaia (scilicet polis) olabileceğini düşündürmektedir. Ayrıca Tıøvaĩos (Tisnaios), nehir

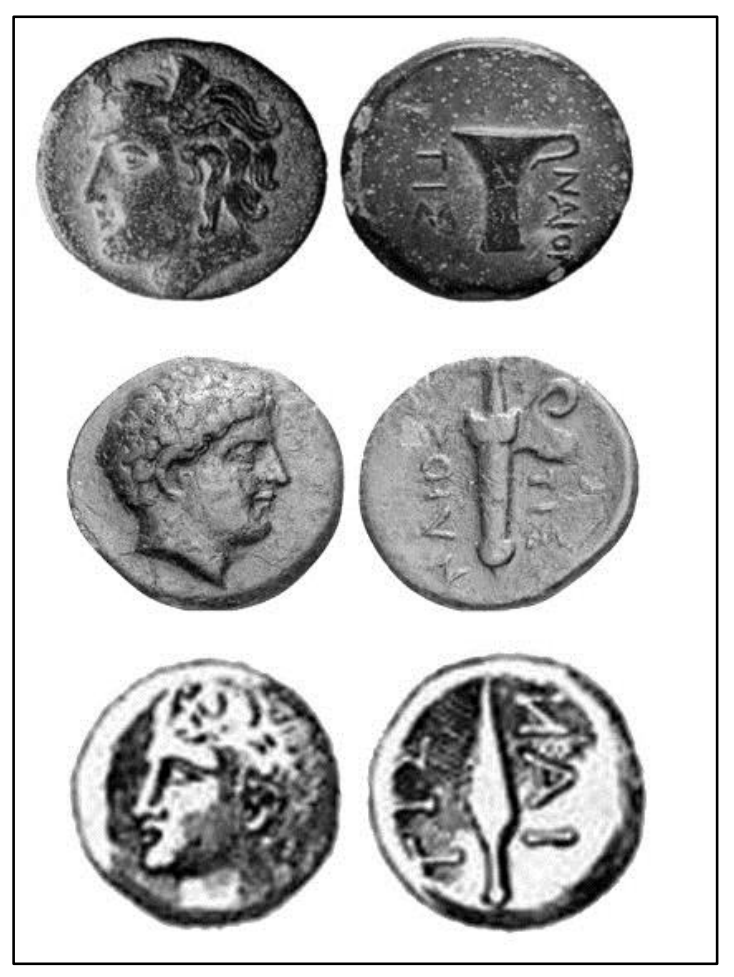

Fig. 6. Tisna Kenti Sikkeleri (Wroth 1984, PI. XXIX; Babelon 1910, No. 2080)

14 Doğer 2017, 78-79.

15 Head 1911, 557: "Tisna, the Titanus of Pliny, nat. V. 30, in the neighbourhood of Cyme and Aegae".

16 Keil 1937, 1481, "Tisna" maddesi: "in die Nähe des äolischen Kyme verwiesene Stadt (...) in einer etwa mittwegs zwischen Kyme und Aigai in einem Nebentale des Koca Çai gelegenen Ruinenstätte".

17 Robert 1970, 169: "Le site a été très vraisemblablement identifié à une ruine située entre Kyme, Myrina et Aigai".

18 Zgusta 1984, 621, no. 1343, Tıøv//a//: “im Nebental des heutigen Koca Çai zwischen Kyme und Aigai”.

19 Tisna'nın MÖ IV. yüzyılda kendi adına para bastırdığı bilinmektedir. Imhoof-Blumel 1883, 275-276, PI. 2931; Wroth 1894, Ixii, PI. xxix-12; Babelon 1910, col. 2074-2080, PI. CLVII 22-27; Imhoof-Blumel 1923, 225226, Taf. IV. Nr. 28-29; Sallet 1987, 284; Schönert-Geiss 1987, 425; Anabolu 1990, 361; 1997, 33, Res. 1; Göktürk 1999, 224, Lev. 3, 35-36; Rubinstein 2004, 1051; Altınoluk 2005, 214-215, Lev. XXXI 1.2, 1.3; Lenger 2011, 156; Dusinberre 2013, 74, Tab. 3.

20 Hansen \& Nielsen 2004, 1051, no. 835, Tisna (Tisnaios): “Lat. 38.45, long. 27.05. The toponym Tisna can be reconstructed from the city-ethnic attested by $\mathrm{C} 4$ coin legends. Presumably the community took its name from the river Tisna, a personification of which was depicted on Tisna's coins". 
tanrısının ismi olmasının yanı sıra kentin ethnikon'u (Tisnalı) olarak da kullanılmış olabilir.

TIINAION (Tisnaion) lejandı, eğer bu kelime neutrum genus'unda ise, hem kentin isminin, Gryneion gibi Tisnaion da olabileceğini hem de Tisnaion'un, Artemision ve Heraion gibi bir kelime olup, "Nehir Tanrısı Tisnaios'un Tapınağı veya Kutsal Alanı" anlamını taşıyabileceğini düşündürmektedir.

Zgusta'ya bakılırsa TIENAION genitivus plurale'dir". Eğer öyle ise, anlamı "Tisnalıların" olur ki bu durumda, Tıøvaĩos kelimesinin, kentin ethnikon'u olabileceği düşüncesi kuvvetlenmektedir.

Plinius (MS 23-79), Naturalis Historia'da Tisna kentini "Titanus" olarak kaydetmiştir. Hellence formu Titanos ise, Tisnaios-Titnaios'dan dönüşmüş görünmektedir. Öyle ise, " $s$ " harfinin " $n$ " harfi önünde " $t$ " harfine dönüşmesine bakarak, kentin diğer isim formlarının Titna, Titnai, Titnaia, Titnaion olabileceği ileri sürülebilir.

Titanus, Aetolia'da bir nehrin; Morea'da (Peloponnesos?) bir dağın, bir ırmağın ve bir kentin de ismidir ${ }^{22}$. Titana, Sikyonia'da bir bölgenin (khorion), Thessalia'da bir kentin adıdır ${ }^{23}$. Tissai, Sicilya'da bir bölgenin (khorion) ismidir ${ }^{24}$. Belki Tisna kenti de "Tissa" veya "Tissai" ismini taşımış olabilir.

Herodotos zamanında muhtemelen "kent" olmayan Tisna, Plinius zamanında "kent" olarak Titanus ismiyle Aiolis kentleri arasında yerini almıştır. Keil'a göre Tisna, "kent" statüsünü kaybetmiş ve Kyme veya Aigai kentlerinden birine "köy" olarak bağlanmıştır ${ }^{25}$.

Kentte 2019 yılında devam eden çalışmalarda 24 adet sikke bulunmuştur. Bunlardan iyi durumda ve lejandları okunabilen 15 sikkenin 9'unun Tisna sikkesi olduğu anlaşılmıştır (Fig. 7). Koleksiyon ya da müze arşivlerinde çok sayıda örnekleri ile bilinen Tisna sikkelerinin ilk kez bilimsel bir arkeolojik çalışma neticesinde arazide bulunan örneklerinin oransal dağılımının, araştırılan alanın Tisna olduğunu düşündüren bir veri olduğu ileri sürülebilir.

Ayrıca Plinius'un Titanus-Tisna'nın yeri ile ilgili

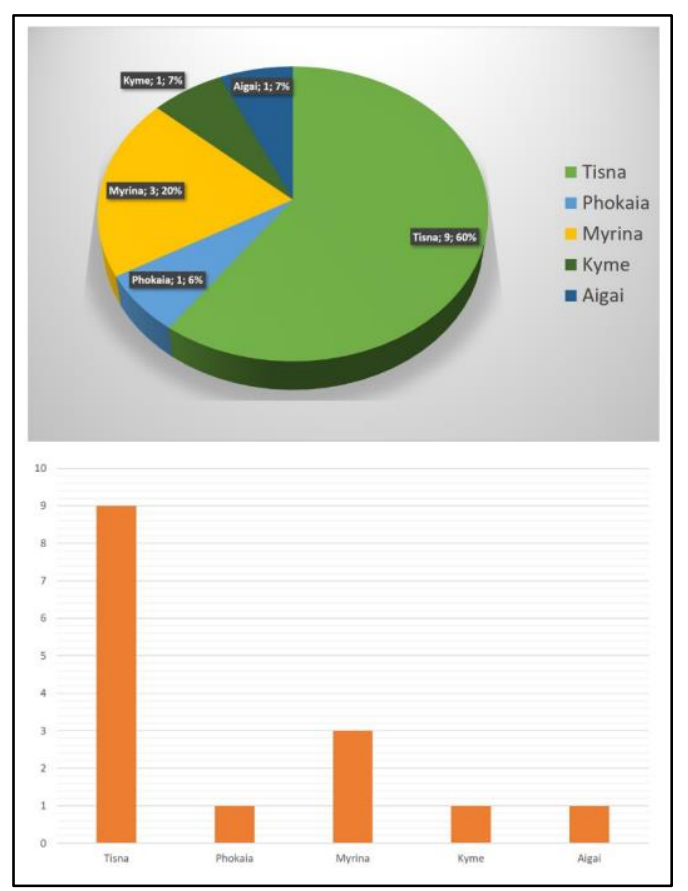

Fig. 7. Tisna Antik Kenti ve Yakın Çevresi 2018 ve 2019 yılı Yüzey Araştırmaları verilerine göre Sarıkale Tepe'de bulunan sikkelerin kentlere göre oransal ve sayısal dağılımı olarak aktardığı konum bilgilerini sağlayabilecek başka hiçbir arkeolojik alanın var olmayışına ve


Numorum'da 557. sayfada böyle bir değerlendirme (ismin çoğul in hali) yer almamaktadır.

22 Pye 1803, (sayfa numarası verilmemiştir), "Titanus" maddesi.



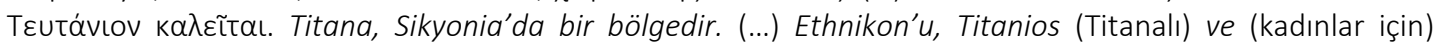



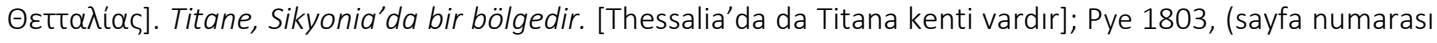
verilmemiştir), "Teutanion" maddesi.

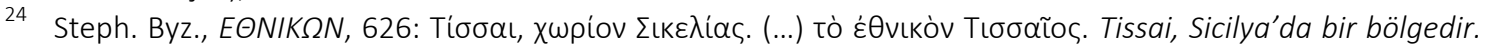
(...) Ethnikon'u, Tissaios'tur (Tissailı); Pye 1803, (sayfa numarası verilmemiştir), "Tissa, Tissae, Tisse" maddeleri.

25 Keil 1937, 1481, "Tisna" maddesi: "wir dürfen annehmen, daß die Siedlung ihr Stadtrecht verlor und als Kome einer der benachbarten Städte attribuiert wurde". 
Tisna'yı belgeleyen herhangi bir yazıtın henüz bulunamamış olmasına rağmen Sarıkale Tepe'nin sunduğu güçlü arkeolojik yüzey buluntuları Tisna antik kentinin burada olduğu düşüncesini desteklemektedir. Tüm bu veriler, Aiolis Bölgesi'ndeki Tisna kentinin, Myrina-Kyme-Aigai kentlerinin egemenlik alanlarının (khora) yakınında (Fig. 1) ve bugün İzmir ili, Aliağa ilçesi, Uzunhasanlar ve Karakuzu mahallelerinin sınırında yer alan Sarıkale Tepe ve Kocakale Tepe'de olduğuna işaret eder görünmektedir.

Sarıkale Tepe 1 No'lu Tümülüs'ün yazıtı, Nikon'un Euboia'daki Karystos kentinden (Fig. 8) Sarıkale Tepe ile Kocakale Tepe'de olduğu düşünülen Tisna'ya geldiğini ancak Tisna vatandaşı olmadığını ve orada öldüğünü belgelemektedir. Karystoslu Nikon'un ayrıntılı kimliği ve neden Aiolis'e Tisna'ya geldiği hakkında yeterli bilgi henüz bulunmamaktadır. Sarıkale Tepe 1 No'lu Tümülüs'ü ise "Karystoslu Nikon'un Tümülüs'ü" olarak adlandırabiliriz.

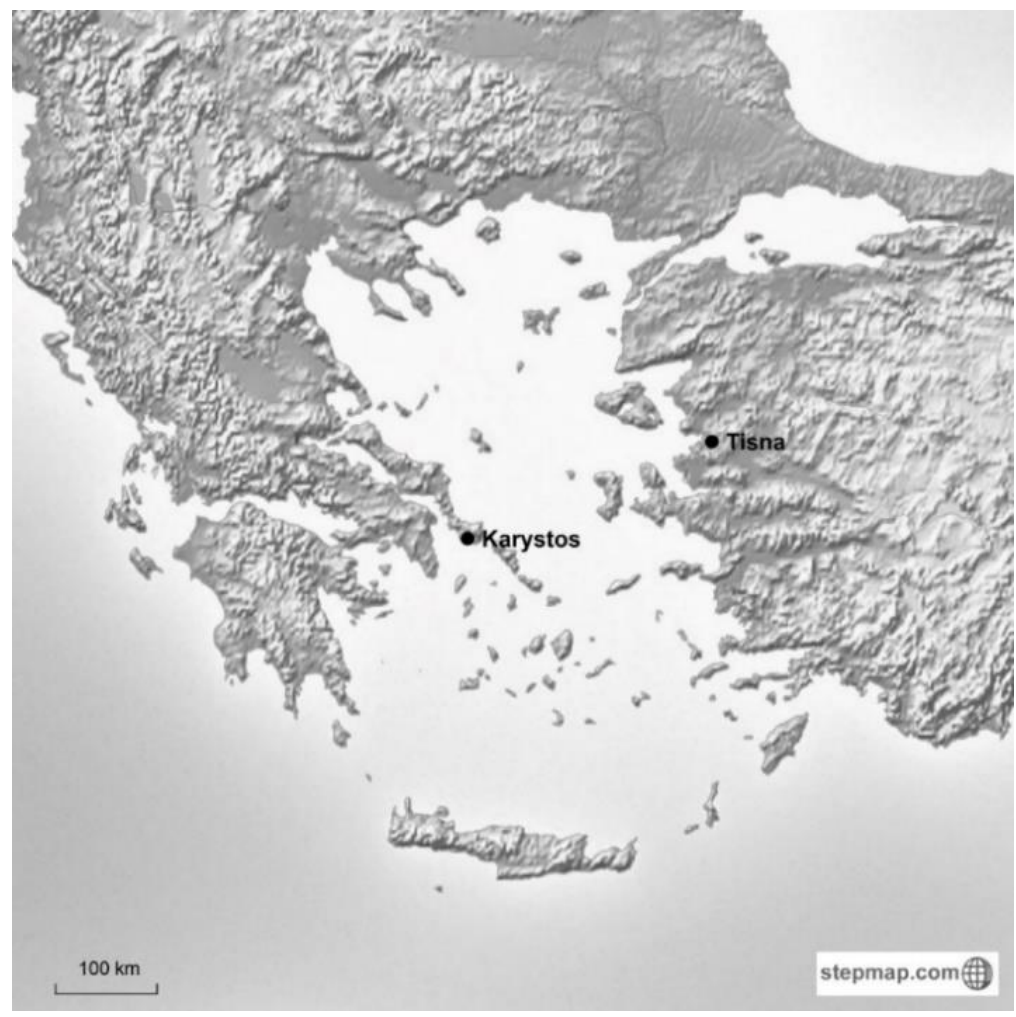

Fig. 8. Tisna ve Karystos'un Konumunu Gösterir Harita (stepmap.com'da tarafımızca hazırlanmıştır)

2018 ve 2019'daki araştırmalar, yüzey araştırması verilerinin ve önümüzdeki yıllarda devam edecek yüzey araştırması ve kazı çalışmalarının Sarıkale Tepe ve Kocakale Tepe'deki kalıntıları aydınlatacak veriler sağlayabileceğini göstermiştir. 
Altınoluk 2005

Anabolu 1990

Anabolu 1997

Babelon 1910

Bean 2001

Conze 1911

Doğer 2017

Dusinberre 2013

Erdan \& Tiro 2018

Göktürk 1999

Hansen \& Nielsen 2004

Hdt.

Head 1911

Imhoof-Blumer 1883

Imhoof-Blumer 1923

Keil 1937

Kiepert 1890

Lenger 2011

Leschhorn \& Franke 2002

Plin. nat.

Potttier \& Reinach 1886

Pye 1803

PW (bk. Keil 1937)

Reinach 1891

Robert 1970

\section{KAYNAKÇA}

Z. S. Altınoluk, Sikkelerin Işığında Küçük Asya'da Irmak Tanrıları. İstanbul Üniversitesi, Sosyal Bilimler Enstitüsü, (Yayımlanmamış Doktora Tezi), İstanbul 2005.

M. U. Anabolu, "Ege Bölgesi Irmaklarının Düşündürdükleri". XI. Türk Tarih Kongresi- I. (1990) 359-365.

M. U. Anabolu, "Yunan-Roma Dönemi Anadolu Sanatında Boynuzlu Figürler". Belleten LXI/230 (1997) 33-35.

E. Babelon, Traité des monnaies grecques et romaines (Vol. 2). Ed. E. Leroux. Paris 1910.

G. E. Bean, Eski Çağda Ege Bölgesi. Çev. İ. Delemen. İstanbul 2001.

A. Conze, "Eine Griechhische Stadt". JdI XXV (1911) 1-12.

E. Doğer, Aliağa Tarihi: Illk Çağ’dan 21. Yüzyıla. Ankara 2017, Aliağa Kent Kitaplığı Dizisi No: 4.

E. R. M. Dusinberre, Empire, Authority, and Autonomy in Achaemenid Anatolia. Cambridge University Press 2013.

E. Erdan \& A. O. Tito, "Myrina Territoriumundan Bir Arkeolojik Yerleşim: Tisna (Tišna?)”. Eds. M. Çekilmez \& E. Dereboylu Poulain \& E. Erdan, Myrina ve Gryneion Arkeolojik Yüzey Araştırmaları (MYGAR): Son Araştırmalar ve Disiplinler Arası Çalışmalar. 2. Cilt. (2018) 89-101.

T. Göktürk, "Aeolis ve Lesbos Şehir Sikkeleri". Anadolu Medeniyetleri Müzesi 1998 Yıllığı. Ankara (1999) 219-256.

M. H. Hansen \& T. H. Nielsen, An Inventory of Archaic and Classical Poleis. Oxford 2004

Herodotos, Historiai, Books I-II. Çev. A.D. Godley. Harvard University Press 1996.

B. V. Head, Historia Numorum. A Manuel of Greek Numismatics. New and Enlarged Edition. Oxford 1911.

F. Imhoof-Blumer, Monnaies Grecques. I'Académie Royale Néerlandaise des Sciences, Paris 1883.

F. Imhoof-Blumer, Fluss und meergötter auf griechischen und römischen münzen (personifikationen der gewässer). Au siège de la Société, Soc. École d'Horlogerie, Genève 1923.

J. Keil, "Tisna”. PW 2 R. 12 Halbband. (Timon bis Tribus). Stuttgart 1937.

H. Kiepert, Specialkarte von Westlichen Kleinasien. De Gruyter, Berlin 1890.

D. S. Lenger, "Nerede Basıldığı Bilinmeyen OY Lejandlı Sikkeler". MJH I/2 (2011) 151-161.

W. Leschhorn \& P. R. Franke, Lexikon der Aufschriften auf griechischen Münzen. Band I. Wien 2002.

Plinius, Naturalis Historia, Libri III-VII. Çev. H. Racham. Harvard University Press 1961.

E. Pottier \& S. Reinach, Terres Cuites et Autres Antiquités trouvées dans La Nécropole de Myrina. Paris 1886.

Ch. Pye, A New Dictionary of Ancient Geography. London 1803.

Paulys Real-Encyclopädie der classischen Altertumswissenschaft.

S. Reinach, Chroniques D' Orient. Documents sur les Fouilles et Découvertes dans l'Orient Hellénique de 1883 a 1890. Paris 1891.

L. Robert, Études Anatoliennes. Recherches sur les inscriptions grecques de I'Asie Mineure. Amsterdam 1970. 
Rubinstein 2004

Sallet 1987

Schönert-Geiss 1987

Steph. Byz., $E \Theta N I K \Omega N$

Strabon, Geographika

Wroth 1894

Zgusta 1984
L. Rubinstein, "Aiolis and South-western Mysia". Eds. M. H. Hansen \& T. H. Nielsen, An Inventory of Archaic and Classical Poleis: An Investigation Conducted by The Copenhagen Polis Centre for the Danish National Research Foundation. Oxford University Press 2004, 1033-1052.

A. Sallet, Zeitschrift für Numismatik. Weidmannsche Buchhandlung, Berlin 1987.

E. Schönert-Geiss, "Einige Bemerkungen zu den Prämonetären Geldformen und zu den Anfängen der Münzprägung”. Klio 69 (1987) 406-442.

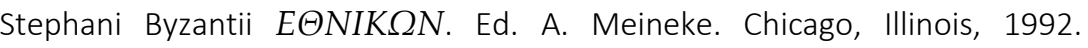
(Unchanged Reprint of the Edition, Berlin, 1849).

The Geography of Strabo Vol. V with an English translation by $\mathrm{H}$. L. Jones. Harvard University Press [The Loeb Classical Library] 1961.

W. Wroth, Catalogue of the Greek Coins of Troas, Aeolis and Lesbos. British Museum, London 1894.

L. Zgusta, Kleinasiatische Ortsnamen. Heidelberg 1984. 